\title{
Design and Implementation of Non-layered 3-Dimensional Orebody Modeling System
}

\author{
Jiming Yao, ${ }^{*}$ Yajing Liu \\ College of mining engineering, North China University of Science and Technology, Tangshan 063009, Hebei, \\ China. \\ * Corresponding author.; Email:Jimingy@126.com \\ Manuscript submitted July 10, 2016; accepted October 12, 2016. \\ doi: $10.17706 /$ jsw.12.1.35-44
}

\begin{abstract}
Because of diversity, complexity and poor information about non-layered orebody, it is difficult to be accurately described by regular geometry model. Mining engineers couldn't accurately estimate the space distribution law of orebody's grade, quality and the total reserve according to the traditional 2-dementional (2D)graphics. So it is necessary to accurately establish non-layered orebody model by a flexible, simple and rapid method. Non-layered 3-dimensional (3D) orebody modeling system was designed based on the analysis of three dimensional data model application. This paper outlines the overall design ideas about the system, and it mainly elaborated how to establish the 3D orebody modeling and how to realize the main function, which has solved the orebody internal model and surface model of integrated modeling. The space characteristics of orebody can be visual analyzed and observed. The system can provide accurate, comprehensive and scientific basis for decision making of mining enterprises on design, production and management.
\end{abstract}

Key words: Orebody, 3D data model, integrated modeling, design and implementation.

\section{Introduction}

The non-layered orebody is a 3D solid buried underground, which often has an irregular and complex shape, and different properties of each part of the internal orebody. 3D orebody is far more complicated than the 3D surface object, and the data acquisition of which is more special. In this special environment, the 3D data model research of orebody has challenging and practical significance. If the orebody model established is not accurate enough, geologists and mining researchers could not make subjective prediction to morphological characteristics and reserves of the orebody. Since the 1990's, many underground 3D visualization softwares had been developed by some international mining software company, which not only could establish geological modeling, and design the open-pit and underground mining, preparation of schedule, 2D and 3D display, but also had function of visualization or images simulation [1]-[4]. However these softwares couldn't be generalized to China because of difference of mining management system. Meanwhile the research of non-layered 3D orebody modeling started late in China, and a lot of work had just started [5]-[10]. To most of the small and medium-sized mines in China, geologists still use the way of manual drawing to delineate the boundary of orebody, and judge the whole orebody form based on 2D model. But in the case of relatively large data, the manner of working could not satisfy the requirements obviously. Then the most important task to mining researchers is to establish the 3D model of orebody. At present, an ideal method of non-layered orebody modeling can not only ensure the precision of the model, 
but also effectively describe the internal properties of orebody, which main integrates two kinds of techniques. First, we can use surface modeling method to establish the boundary of orebody, then the internal block of orebody is described by voxel model. Just the domestic three-dimensional data model theory is not in-depth and incomplete, and the mixed data model of theoretical research and practical application progress is slow. So in building integrated model of true three dimensional non-layered orebody model still needs further research. At the same time, we urgently need a set of data processing, orebody modeling visualization and calculation of reserves, and other functions of practical and mature, the bedded orebody modeling system.

\section{Data Flow of the System}

3D non-layered orebody modeling system is developed by the joint laboratory of Peking university and Beijing dragon soft science and technology development co., LTD. It is a subsystem of which is specifically for non-layered deposits of the management information system platform to test (as shown in Fig. 1). The subsystem adopts the SVA[11](Surface-Volume-Analogical Right Triangular Prism) mixed data model to establish the three dimensional non-layered orebody model, the analysis of orebody internal and external attribute has obvious advantages. At present the subsystem can provide $3 \mathrm{~d}$ visualization modeling function to the users, which includes drilling data modeling, the bedded orebody modeling, surface modeling, internal block section interpolation calculation of reserves, orebody data model coding compression storage, and other functions. The data flow of entire process of system modeling is shown by the arrows in line in figure 1, the data of whole non-layered ground measurement space management information system are input, edited, managed and extracted in the database management system of geologic measurement which is the subsystem of LRGIS, which can provide prospecting line coordinate data, drilling data and survey data, borehole sample data and other information for $3 \mathrm{~d}$ orebody modeling. Data is extracted from the database, and then it is brought up in a two-dimensional LRGIS graphics management system to draw the section line and plane line drawing, which will be passed to the visualization subsystem of three-dimensional orebody modeling to establish the bedded orebody surface model. Among them, the borehole sample data points can be extracted directly used for three dimensional non-layered orebody internal block piece of data interpolation model, and integrated model of orebody is established, and then calculation of reserves.

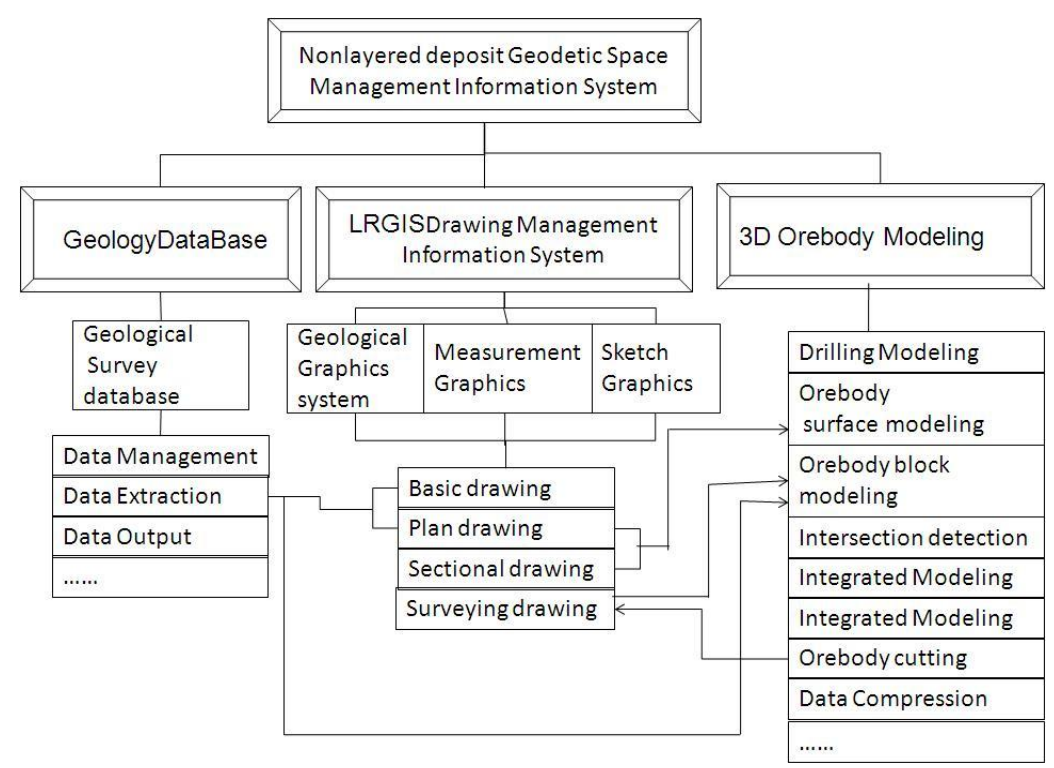

Fig. 1. The basic structure and function of system. 
Thus the system formed two data flows including 'data collection-data management-2D drawing-3D orebody modeling-reserve calculation--data compression' and 'data collection-data management-2D drawing-3D orebody modeling--geological plane-mining design', which changed the original data flow about 'raw data-geological profile-geological plane'. Finally, the existing data flow could really realize the 'combining exploration with exploiting' and 'dynamic modification'. The data could communicate, modify and renew each other in system,

\section{The Realization of System Main Function}

It is difficult to use a general $3 \mathrm{~d}$ data model to express the complexity of the bedded orebody model based on the analysis the modeling method of existing $3 \mathrm{~d}$ data model. Consensus view of academia think that the universal model is not necessary, but the application of purposeful targeted research should be carried on to different study fields, and they claim to conduct research in the form of mixed data model. Therefore, the SVA integrated modeling method was used which can relatively accurately describe the non-layered orebody modeling $3 \mathrm{~d}$ spatial shape, realize the efficient storage of the information of mineral resources, the accurate simulation and three-dimensional expression and the precise calculation of reserves [12]-[14].

The non-layered orebody space management information system mainly includes geological and surveying database, 2D graphics and reserve calculation and three managerial subsystems.

\subsection{Geological and Surveying Database Managerial Subsystem}

Geological and surveying database managerial subsystem includes data management, data extraction, report output and so on.

1) Geological exploration data management. Which includes input, save, query and edit about geological exploration line data, borehole data, formation data, boring inclinometer data, hydrological data and so on.

2) Production exploration data management. Which includes input, save, query and edit about production exploration line data, production borehole data, borehole formation data and so on.

3) Data extraction from section. Which includes data extraction function, the data includes geological exploration line section, production exploration line profile and traverse points.

4) Report output. Which includes report printing of production borehole data and drilling quality.

Fig. 2 is the management interface of the data of geologic prospecting line.

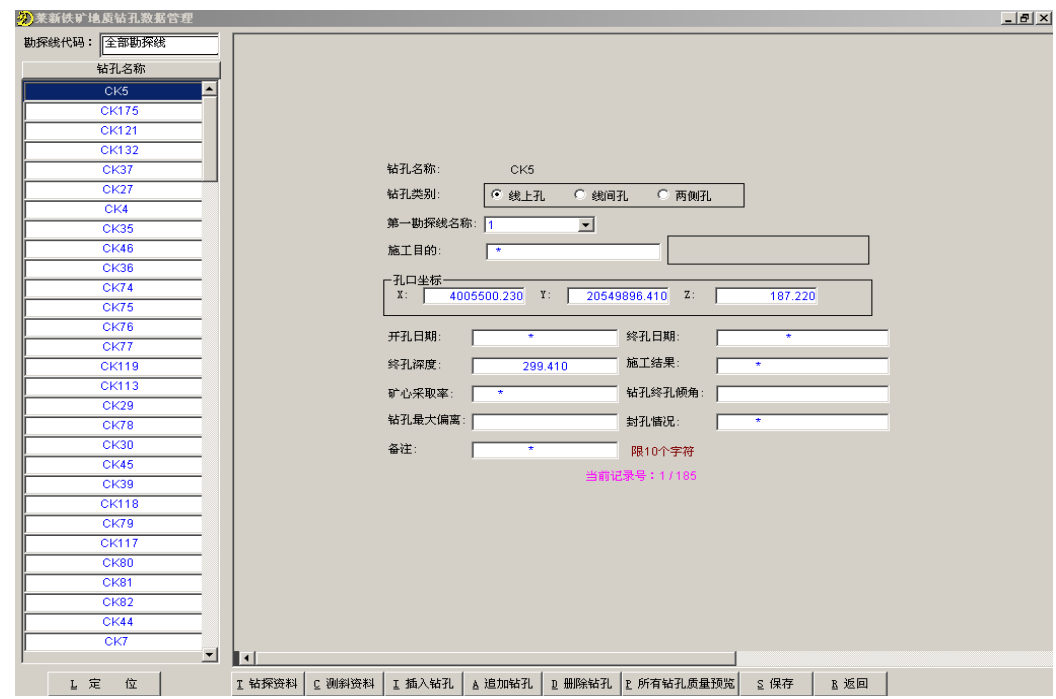

Fig. 2. The management interface of the data of geologic prospecting line. 


\subsection{Two-Dimension Graphic Subsystem}

The 2D graphic subsystem which includes some functional modules contains basic cartography function,flat drafting,section drafting and survey drafting. The exploration line section drawing and the plane drawing function are mainly introduced as following:

\subsubsection{The function of sectional drawing}

1) Reading profile data function, which can draw the grid line, drilling data and see ore point automatically after projection according to the drilling data and see ore point data, which extract from the database.

2) Drawing the orebody profile contours in 2D interactive, which provides the spline curve and allows the user to delineate the orebody contour interactively;

3) According to the measurement data in the database, the system can draw the roadway section of measurement automatically;

4) Generating the frame, illustrations, and annotation automatically;

5) Corresponding the section map and plane map. It includes reading the adjacent plan map, corresponding the sampling points between the section map and plane map , then project the drilling point and see ore point to the plan map;

6) Input and output functions of orebody contours. The output function can provide two-dimensional contour data to three-dimensional modeling subsystem. The input function is reading the contour data from three-dimensional subsystem to two-dimensional graphics system.

Fig. 3 is a section map view of geological prospecting line.

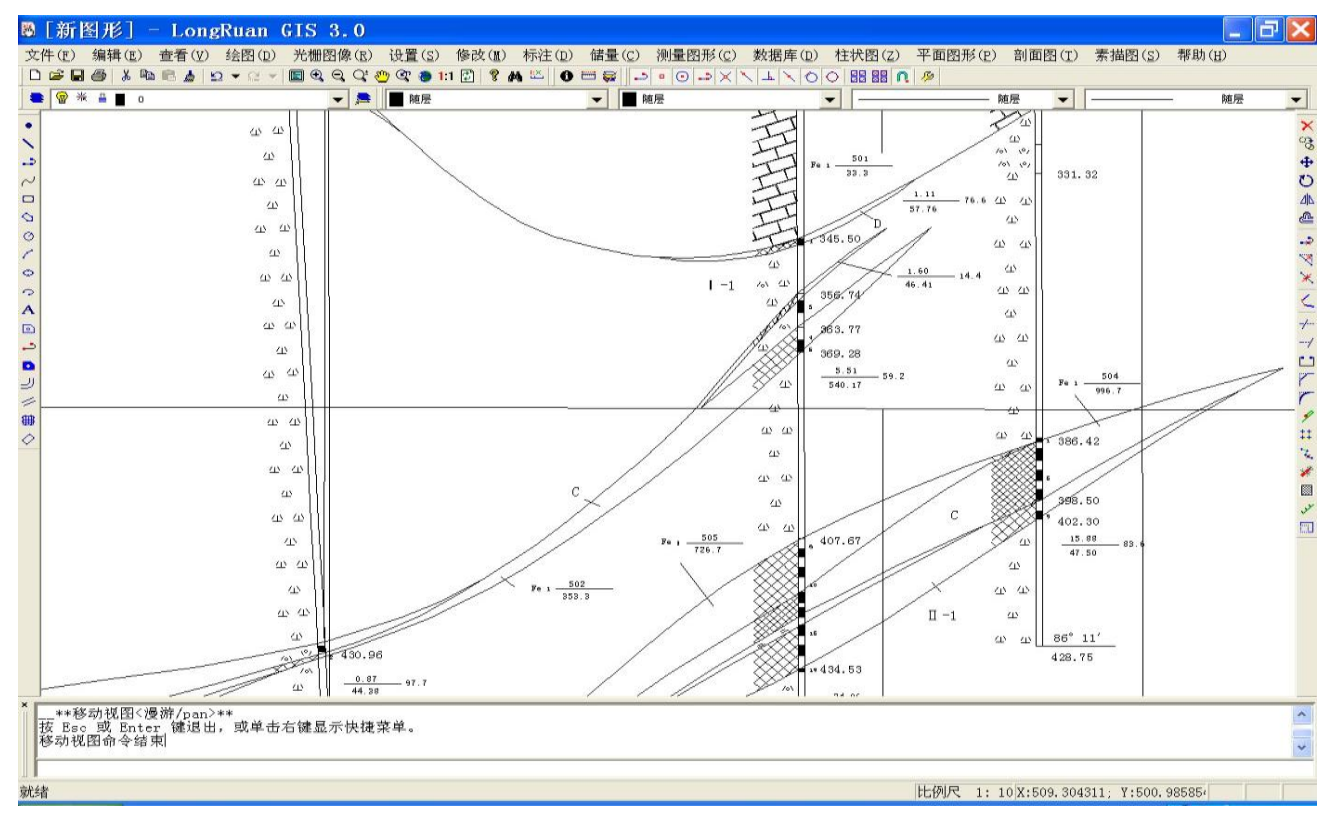

Fig. 3. The section of geologic prospecting lines.

\subsubsection{The function of drawing the plane map}

1) The function can spot the laneway automatically, which can extract the measurement data from the database, then generating the measuring figure of laneway automatically;

2) Transferring plan data to the section map. Which transfer the data of fault, laneway and orebody contour line to section map, then modify the section map according the location of plan map;

3) Computing the reserves and area automatically;

4) Generating the three-dimensional laneway; 
5) Generating curve chart related hydrology according the raw data;

6) Reading the drilling data from the database, which can generate the column of single drill hole of the geological exploration borehole and the production exploration hole.

Fig. 4 is plan view of excavation.

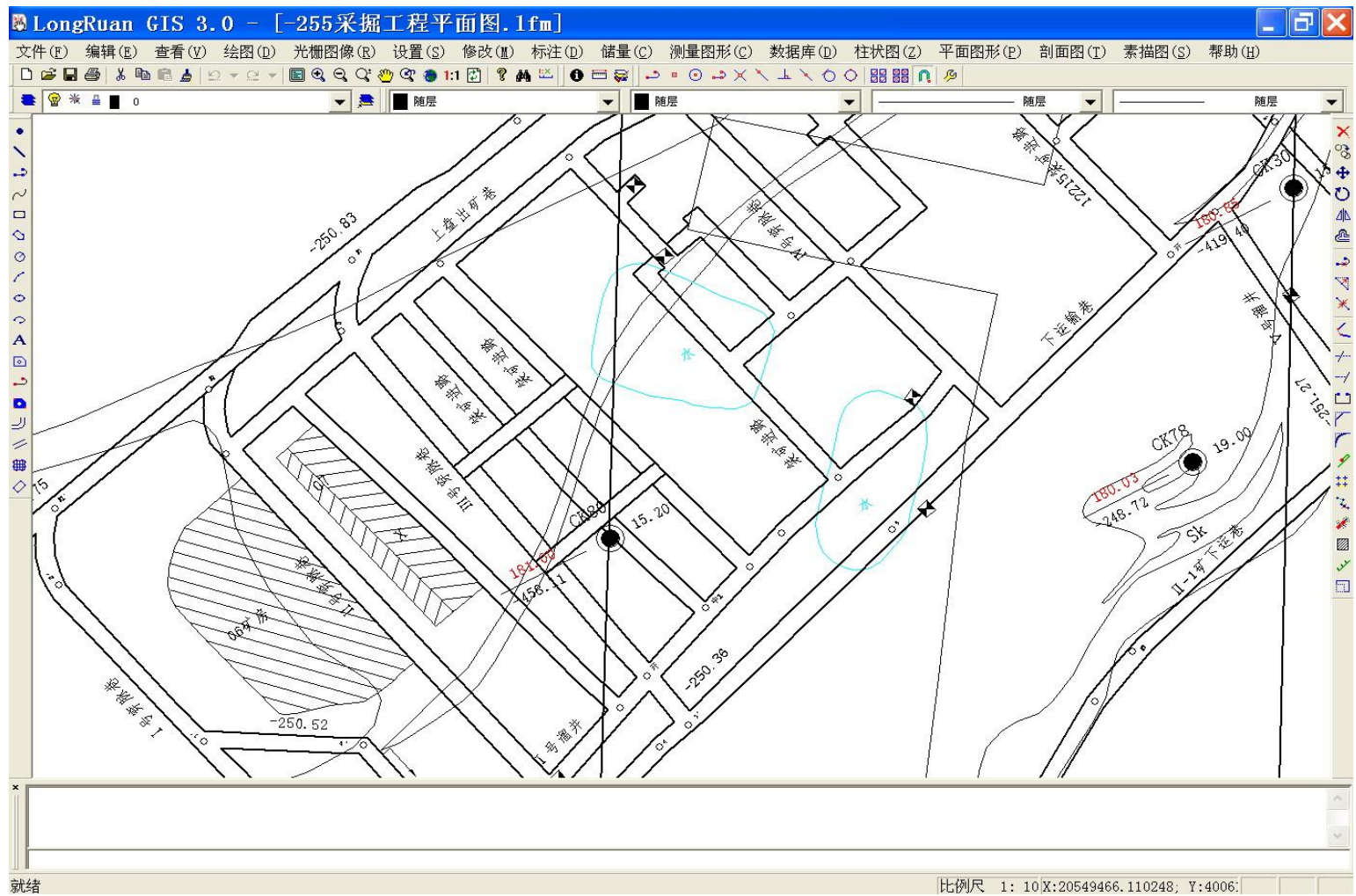

Fig. 4. Plan view of excavation.

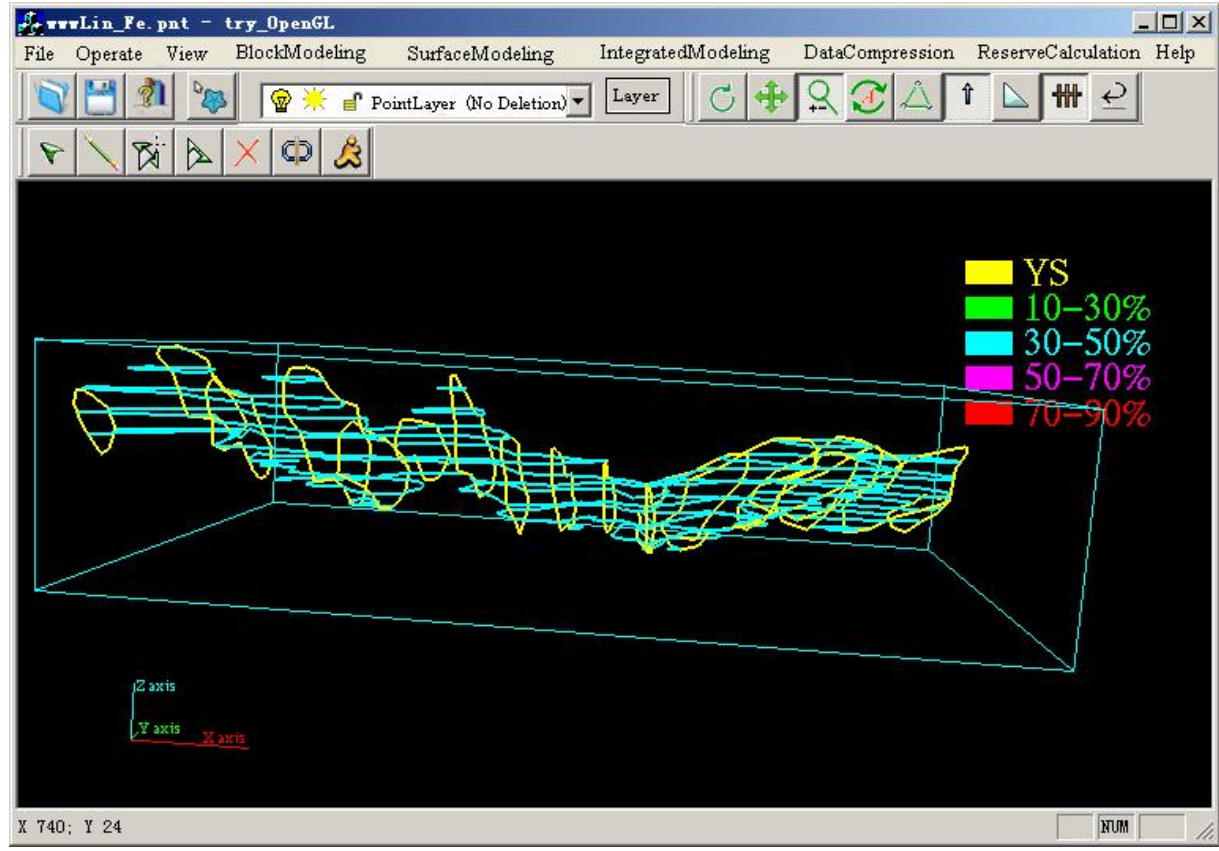

Fig. 5. The contour extraction of Plans map and sections of map.

\subsection{Orebody Three Dimensional Visualization Modeling}




\subsubsection{The establishment process of orebody surface model.}

\section{Extract orebody contour [15]}

To see from the production or geological prospecting line section map to extract for delineating orebody boundary according to the point which discovery the ore firstly in the drilling, Figure 5 is extracting contour map

from the plan map and the section map. Which is in a certain iron ore, orebody shape is more complex, cystic, in the west have a branch. Prospecting line azimuth angle is $136^{\circ}$, there are 15 lines of geological exploration, branch at -10 exploration lines occur.

Establish the surface model of orebody

System provides the functions of modeling between two sections, control line, modeling between the section and point, and modeling inside section, etc, which can build up the surface model of for complex orebody. Control line modeling refers to the modeling of the shortest diagonal after the user interaction to add line. Crossed flat, section orebody surface model is using the shortest diagonal method, which is to extract prospecting line section and plan from $2 \mathrm{~d}$ graphics system to automatically to control each other in the $3 \mathrm{~d}$ modeling. Modeling between section and points refers to the contour line, pointed out the point-to-point, to seal the opening of the model. Inside modeling the section is to profile the delaunary triangulation are closed. Fig. 6 is the result of surface model which is built by contour line extracted from cross flat and section.

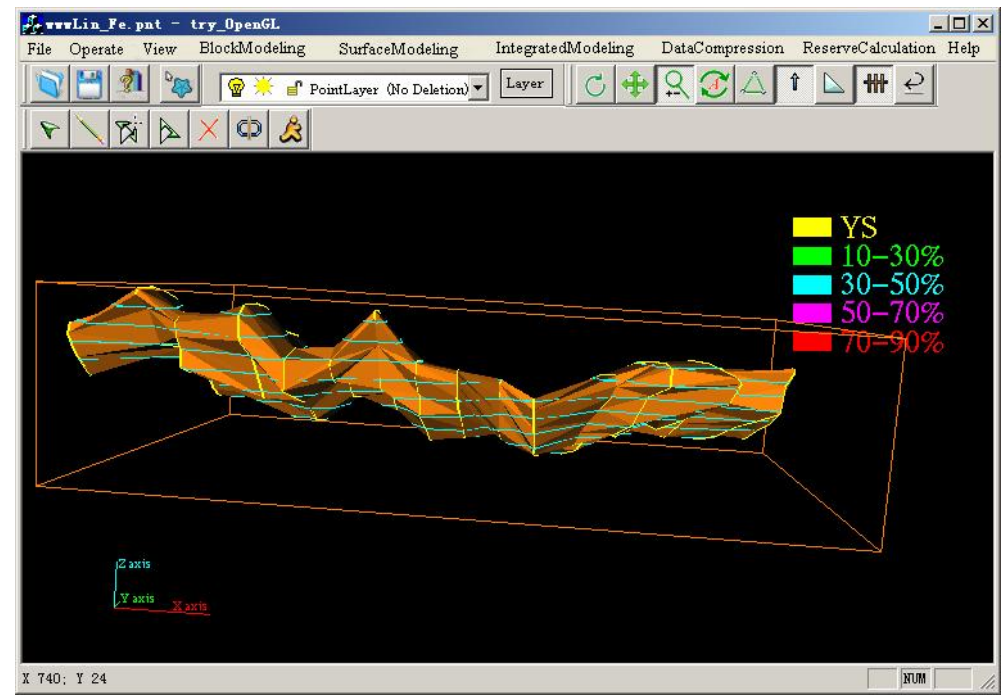

Fig. 6. Using cross and profile of the surface of the orebody model is set up.

\subsubsection{Block modeling of orebody}

The system provides function of establishing the discrete point model, calculating the test function of variation, fitting variation function, cross validation, empty block modeling and block interpolation modeling, and other functions, as shown in Fig. 7, [16]-[18].

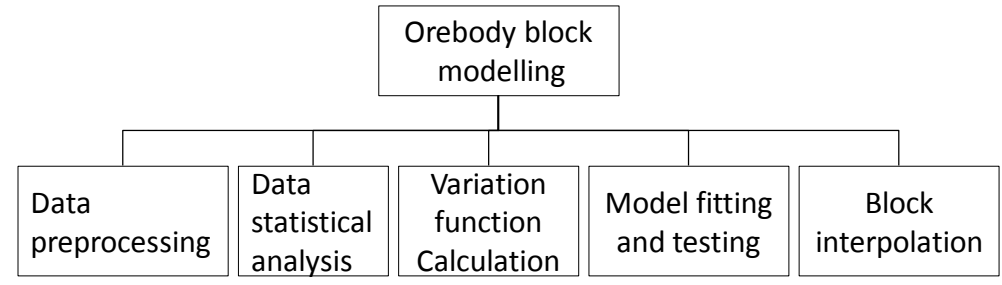

Fig. 7. Orebody block Duan Jianmo function. 
1) Data preprocessing function. It includes spatial data checking, logarithmic transformation, standardized transformation, etc.

2) The statistical characteristic analysis function .Basically statistical analysis of spatial data includes statistical characteristics of the spatial data (such as the mean, variance and spatial correlation, etc.), histogram analysis, singular value analysis, etc.

3) The function of spatial variability analysis. Spatial variation function is used to analyze the variability of the spatial data and establish the corresponding mathematical model, including spatial variation function calculation, more direction variation function diagram, single direction variation function fitting and model fitting and inspection, etc. Among them, model fitting including direct method and multiple regression fitting method, inspection using cross validation method to verify this fitting method. Block interpolation function includes the use of inverse distance power method, the three-dimensional ordinary kriging interpolation method, and other functions to achieve orebody block grade data interpolation.

4) For a simple deposit grade distribution uniformity and simple shape orebody, the inverse distance power method usually is used, otherwise, for the uneven distribution of grade and complex shape orebody, the ordinary kriging method of interpolation is used. Users can build the orebody segment grade data model through choosing different methods according to their needs.

System provides a lot of operation including the extraction of discrete data of borehole see mines, variation of orebody internal structure function analysis, nested structure, empty block modeling, segment interpolation modeling, cutting of orebody and transparent switch operation.

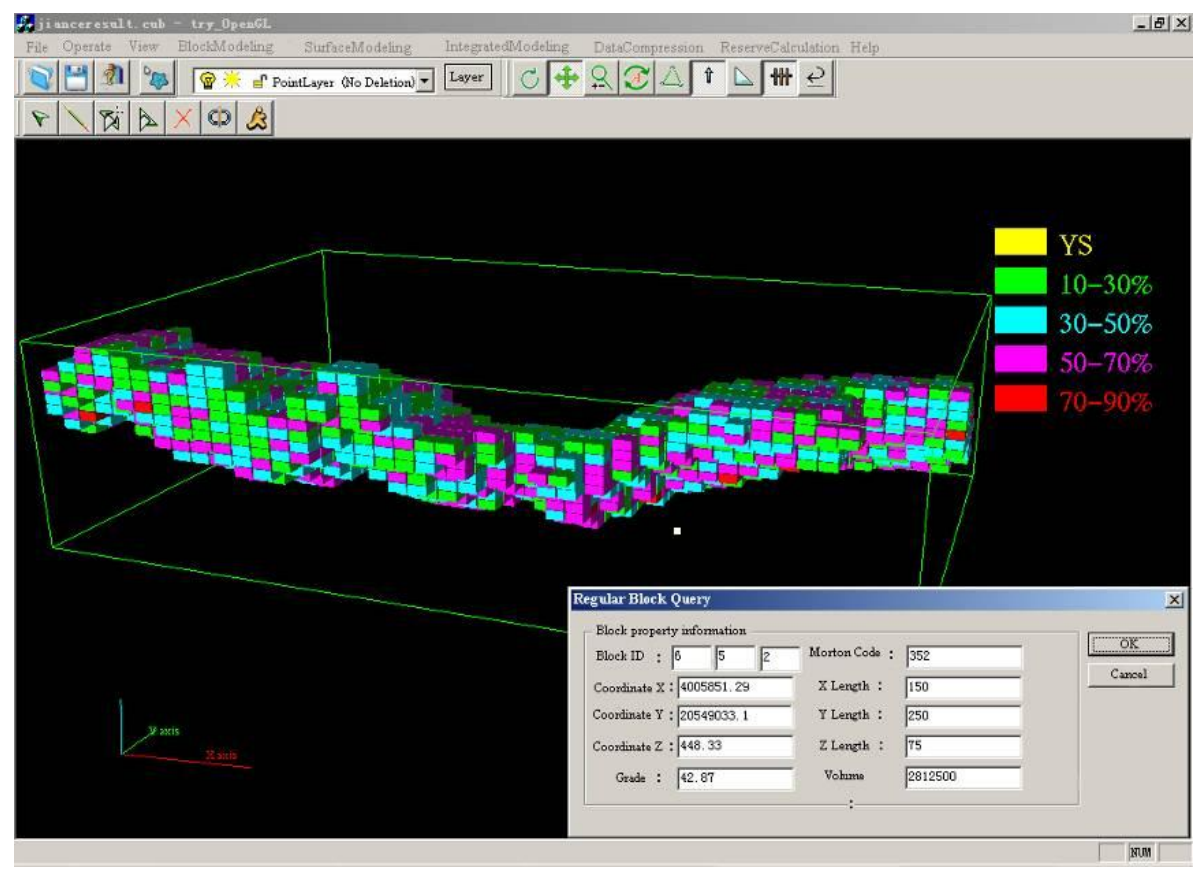

Fig. 8. Orebody segment model and information query interface.

Analyzing some mine data, calculating the test variation function, and getting on the grade of the differ discrete points in $\mathrm{X}$ and $\mathrm{Y}$ direction whose distance is 80 meters each other, then search the grade of the differ discrete points in $\mathrm{Z}$ direction whose distance is 30 meters each other. According to the grade of the discrete points in the $\mathrm{X}, \mathrm{Y}, \mathrm{Z}$ three directions and the number of pair data at a given distance. Then three directions variational function figure is established through the achieved data. The $\mathrm{X}, \mathrm{Y}, \mathrm{Z}$ three directions of variation, the nugget effect and high arch are all get by direct method fitting spherical model, through 
cross validation, model meets the requirements. And then, a piece of orebody model is set up, the system offers the query function on properties of each block of, as shown in Fig. 8.

\subsubsection{The integrated model of the orebody}

SVA integrated orebody modeling method is to restrict the ore block model using the surface model of orebody. First, whether block model voxels intersect with the surface of the orebody model or not should be determined. If they are disjoint, the voxels are divided into inside orebody and outside orebody, outside orebody of the voxels does not belong to the orebody, which should not be thought about, the inside orebody of the voxels can be interpolated into block model. If the voxels intersect with the orebody surface model, it will have to be calculated intersection, and then use ARTP ${ }^{[19]}$ voxels for storage. The boundary of orebody model is vector by the method, and it is accurate. At the same time, the data expansion problem does not exist in order to achieve the required precision through the constant subdivision to the boundary of orebody. The 3d visualization orebody whole figure can be obtained using SVA integrated model, as shown in figure 9, which not only can show the whole orebody spatial shape, but also can reflect the grade of orebody parts in spatial distribution, by setting the parameters such as color, texture, light, display the orebody shell and the internal segment, by setting the transparency falsified shell, clear display orebody internal different grade of ore block.

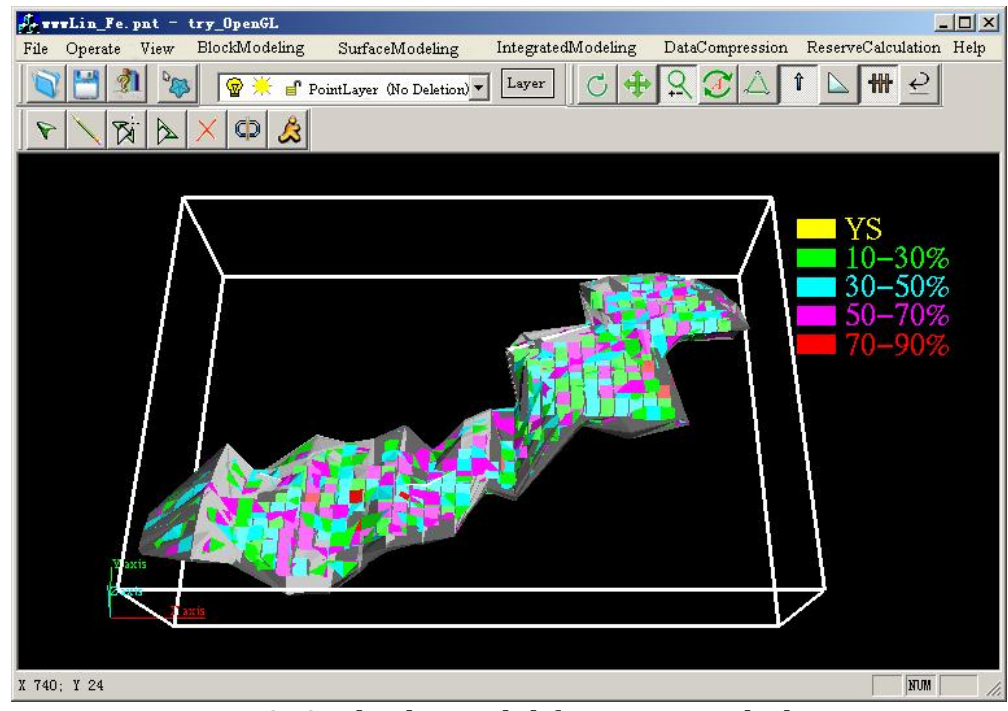

Fig. 9. Orebody model figure as a whole.

\section{The Characteristics of the System}

\subsection{The Traditional Workflow Was Improved}

The operation process of the whole system keeps the traditional methods of work which are familiar with by the domestic users, that is, from drawing the section map then began to work. the traditional workflow of "raw data-geological profile map-geological plan map and mining design" is retained, at the same time provides new work process of "the raw data-geological profile-the 3D orebody model-geological plan-mining design".

\subsection{Establish the Generality of Orebody Model}

System can set up the surface model of the orebody according to the geological plane, section contour line and they control each other. In the process of modeling, the branch, pinchout point and pinchout line and other special situation are all considered. The internal model is established using rule segment 
interpolation method, and the orebody boundary element should be represented using irregular segment. At the same time the whole orebody model plane, section and arbitrary angle cutting are all realized, the expected profile and anticipated plan can be drawn in 2D space. This method increased the orebody internal information compared with the use of solid modeling in the relevant domestic research, and it is suitable for all kinds of complex of bedded orebody structure.

\subsection{The Precision of the Model Volume and the Calculation of Reserves Was Improved}

System can calculate the volume by compute the sum of boundary irregular voxels's volume and internal rule voxels's volume, and then calculating the reserves of orebody model. This method not only enhances the precision of calculation, and analyzes the change regularity and the complex structure of the ore bodies, solves the mineralization model of traditional graphic display and grade, the problem of separating calculation of reserves, which is compared with the method of using cross section method to calculate the orebody volume and reserves through calculating the contour line

\section{Conclusion}

The 3D model of the non-layered orebody was realized in this system, which mainly contained two models about internal and surface of orebody. For internal orebody, we established raster data model which build non-overlapping regular geometry voxels to internal orebody by interpolation to show the internal properties of orebody, then transform the boundaries of internal orebody into irregular geometrical element object which was compatible with vector surface, thus the model can express the characteristics of both internal and shape of orebody. To surface of orebody, we use 3D vector data model to accurately express the shape characteristics of the object. The system could quickly generate geological section, plane view of excavation, bore hole columnar section, hydrologic chart and so on, and it can establish real 3D orebody model which could generate various profile and plan, reserve calculation. On the basis of the above, the mining designer can carry out the design of mining and blasting design conveniently. The application of the system has changed the traditional manual drawing mode, which greatly reduced the workload of the geological, surveying and mining designers. The system is oriented to the non-layered ore application system, and it has a good application prospect in industry.

\section{Reference}

[1] Homepage of Surpac. Retrieved from: http://www.surpac.com.cn

[2] Homepage of DataMine. Retrieved from: http://www.datamine.co.uk

[3] Homepage of Lynx Geosystems. Retrieved from: http://www.lynxgeo.com

[4] Homepage of Mincom. Retrieved from: http://www.mincom.com

[5] Wang, G., Li, R., Carranza, \& E. J. M. et al. (2015). 3D geological modeling for prediction of subsurface Mo targets in the Luanchuan district, China. Ore Geology Reviews, 71, 592-610.

[6] Agoston, M. K. (2005). Computer Graphics and Geometric Modeling. Springer, USA.

[7] Kaan, E. (2012). Computer aided ore body modeling and mine valuation, earth sciences. Retrieved from: http://www.intechopen.com/books/earthsciences/computer-aided-ore-body-modeling-and-mine-val uation

[8] Chen, P. (2005). Research on Three-Dimensional Spatial Data Models and Algorithms in Geology and Mine. Wuhan University.

[9] Wang, E., Sun, L. S., \& Cai, H. C., et al. (2007). Three-dimensional data model of ore body and grade interpolation method study. Geology and Resources, 9.

[10] Sun, S. L. (2007). Research on Ore Body 3D Modeling and Reserves Calculation Key Problems. Northeastern university. 
[11] Liu, Y. J., Mao, S. J., \& Yao, J. I. (2008). Study on spatial modeling of ore body information based on SVA integral. Journal of China coal Society, 5(522-526).

[12] Li, M., Mao, S. J., \& Ma, A. (2006). Building ore body solid model from planar contours. Journal of Computer-aided Design and Computer Graphics. 18.

[13] Hou, J. R., Yin, Z., Li, \& W. M. et al. (1998). Practical Geostatistics. Beijing: Geological publishing house.

[14] Mao Shanjun.(2002). Gray geographical information system - the theory and technology of correct geological spatial data dynamically. Acta Scientiarum Naturalium Universitatis Pekinensis.

[15] Ramazan, S., \& Dimitrakopoulos, R. (2004). Traditional and new MIP models for production scheduling with in-situ grade variability. International Journal of Surface Mining.

[16] Guo, Y. J., Pan, M., \& Wang, Z. (2009). Research on Three-Dimensional Geological Modeling Method Based on Drilling Data and Constraints of Intersected Folded Cross-Sections, Geography and GeoInformation Science.

[17] Grieco, N., \& Dimitrakopoulos, R. (2007). Managing grade risk in stope design optimisation: probabilistic mathematical programming model and application in sublevel stoping. Mining technology.

[18] Liu, Y. Z., Zhang, B., \& Yu, X. X. (2015). Research and application of the ore body three-dimensional mathematical model based on baiyang-chuanxindong ore block in bainiuchang mine. Applied Mechanics and Materials.

[19] Xiong, W., Mao, S. J., \& Ma, A., et al. (2002), A research on geometric modeling of roadway and the key algorithm of coalmine in virtual environment. Bulletin of Surveying and Mapping.

\section{Acknowledgements}

This project is supported by Natural Science Foundation of Hebei Province (Grant No:D2014209253)

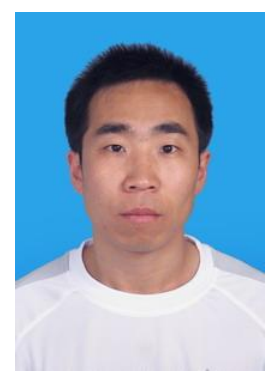

Jiming Yao was born in Hebei China, in 1977. He was graduated from China University of Geoscience in 2009. He received a doctorate degree in mineralogy petrology gitology.

He works at the North China University Science \& Technology from 2009 till now, he teaches the professional courses in the College of Mining Engineering.

Yajing Liu was born in Hebei China, in 1977. He was graduated from China University of Mining and Technology (Beijing) in 2007. She received a doctorate degree in cartography and geographic information engineering.

She worked at the North China University Science \& Technology from 2007 till now, she teaches the professional courses in the mayor of geographic information science. 